\title{
Medizin mit Durchblick - Deutsche Röntgengesellschaft startet Informationsinitiative
}

Sie sehen eine Walnuss? Wir sehen einen Schlaganfall. So lautet der Werbetext eines der Plakatmotive, die in diesen Tagen an die radiologischen Praxen und Institute verschickt werden.

Gemeinsam mit den benachbarten Fachgesellschaften für Nuklearmedizin und Strahlentherapie startete die Deutsche Röntgengesellschaft eine breit angelegte Informationsinitiative. Die Kampagne steht unter dem Label „Medizin mit Durchblick - Die Radiologen und Strahlenmediziner" und umfasst umfangreiches Material für die Patientenkommunikation im Wartezimmer. Zeitgleich geht das Informationsportal www.medizinmit-durchblick.de ins Netz.
Praxisinhaber und Institutsleiter sind herzlich eingeladen, die Materialien für ihre Patientenkommunikation zu nutzen. Die verschiedenen Printprodukte wie Informationsbroschüren und CD-Hüllen für die diagnostischen Daten können im Onlineshop unter www.medizin-mit-durchblick.de/shop zum Selbstkostenpreis bestellt werden.

Weitere Informationen unter: www.medizin-mit-durchblick.de. 